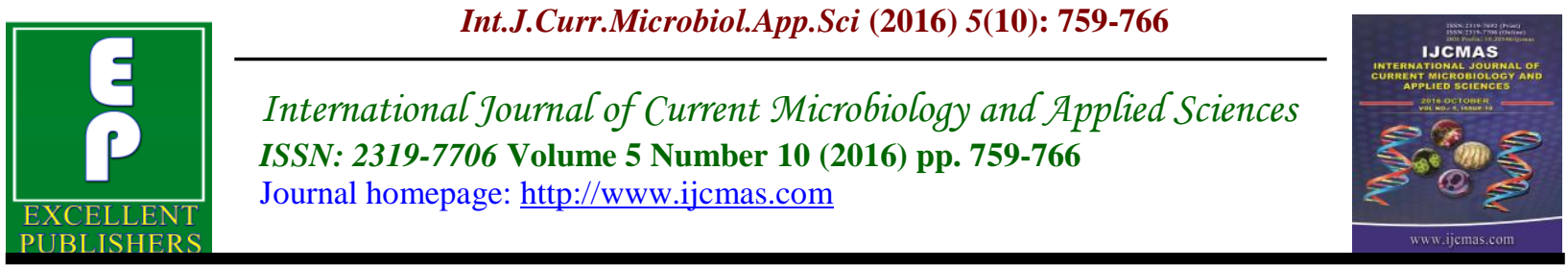

Review Article

http://dx.doi.org/10.20546/ijcmas.2016.510.082

\title{
Heavy Metals Contamination in Water and their Hazardous Effect on Human Health-A Review
}

\author{
Mahipal Singh Sankhla, Mayuri Kumari, Manisha Nandan, \\ Rajeev Kumar* and Prashant Agrawal
}

\author{
Division of Forensic Science, School of Basic and Applied Sciences, \\ Galgotias University, Greater Noida, India \\ *Corresponding author
}

\section{Keywords}

Heavy Metals, Water, Water and their Hazardous Effect on Human toxic.

\begin{tabular}{l}
\hline Article Info \\
\hline Accepted: \\
22 September 2016 \\
Available Online: \\
10 October 2016
\end{tabular}

\section{A B S T R A C T}

The levels of heavy metals contaminations in water like, $\mathrm{Pb}, \mathrm{As}, \mathrm{Cd}, \mathrm{Hg}, \mathrm{Cr}$, Ni etc. in various water sources as ground, surface, tap water etc. Variety of heavy metals, some of them are potentially toxic and are transferred to the surrounding environment through different pathways. The concentrations determined were more than the maximum admissible and desirable limit when compared with the National and International organizations like WHO (2008), USEPA, EUC, EPA. Water may become contaminated by the accumulation of heavy metals and metalloids through emissions from the rapidly expanding industrial areas, mine tailings, disposal of high metal wastes, leaded gasoline and paints, land application of fertilizers, animal manures, sewage sludge, pesticides, wastewater irrigation, coal, Electronic waste. Heavy metal toxicity has proven to be a major threat and there are several health risks associated with it. The toxic effects of these metals, even though they do not have any biological role, remain present in some or the other form harmful for the human body and its proper functioning.

\section{Introduction}

The environmental contaminations by the toxic substances are growing that cause major concern to the local users. A wide range of contaminants are continuously introduced into the aquatic environment mainly due to increased industrialization, technological development, growing human population and exploitation of natural resources, agricultural and domestic wastes run-off. Among these contaminants, heavy metals constitute one of the most dangerous groups because of their persistent nature, toxicity, tendency to accumulate in organisms and undergo food chain amplification and more still, they are non degradable. Heavy metals with adverse health effects in human metabolism (including lead, mercury, cadmium and arsenic) present obvious concerns due to their persistence in the environment and documented potential for serious health consequences. Acute heavy metal intoxications may damage central nervous function, the cardiovascular and gastro 
intestinal (GI) systems, lungs, kidneys, liver, endocrine glands, and bones. It is not possible to completely avoid exposure to toxic metals. Even people who are not occupationally exposed carry certain metals in their body as a result of exposure from other sources, such as food, beverages, or air. It is, however, possible to reduce metal toxicity risk through lifestyle choices that diminish the probability of harmful heavy metal uptake, such as dietary measures that may promote the safe metabolism or excretion of ingested heavy metals (Rajeev Kumar et al., 2014). Due to evolution of technology, the rise of industries at or along the bank of water bodies is one of the main cause of pollution which may cause the health hazards for the population consuming the contaminated water and other related eatables. Many publications are available all around the world consisting the heavy metal detection and have been discussed in the paper. Due to the number of references collected from the variety of sources, some lacks or omissions are possible. Authors have tried to cover maximum number of information, some of them are briefly discussed below:-studied the relationship among sediment, water and fish for their metal concentrations in urban streams of Semarang, Indonesia and found a significant declining trend of lead concentrations with increasing organism size, whereas for two other metals, $\mathrm{Zn}$ and $\mathrm{Cu}$, the concentrations did not depend on the body weight. However, metal concentration in the sediment was the most important factor governing the toxicity of metal in fish body. The fish living in highly polluted sites have also developed a physiological adaption by accumulating a large quantity of metals. Heavy metals in water, vegetation, fishes and other marine food, are one of the main reasons for the environmental contamination. Due to this reason, the detection of heavy metals and their ill effects on the human being are always of concern of a scientist/toxicologist. The toxic effects of heavy metals are long lasting, reason being the non degradation properties of heavy metals. The heavy metals can't be degraded whereas organic contaminants decompose into other chemicals with time. Heavy metals have toxic effects even at low concentration, which may prove lethal to any living being. Their concentration in biota can be increased through bioaccumulations (Widianarko et al., 2000; Ganagaiya et al., 2001). Toxic metals are usually present in industrial, municipal and urban runoff, which can be harmful to humans and biotic life. Increased urbanization and industrialization are to be blamed for an increased level of trace metals, especially heavy metals, in our waterways (Seema). Many dangerous chemical elements if released into the environment, accumulate in the soil and sediments of water bodies (Abida et al., 2009).

\section{Source of Contamination of heavy metal in Water}

\section{Natural sources}

In nature excessive levels of trace metals may occur by geographical phenomena like volcanic eruptions, weathering of rocks, leaching into rivers, lakes and oceans due to action of water (Bagul et al., 2015).

Anthropogenic Sources: Small amounts of heavy metals are released while mining and uncontrolled smelting of large quantities of metal, ores in open fires. With the industrial revolution, metals were extracted from natural resources and processed in the industries from where heavy metals passed on into the atmosphere. Similarly traces of heavy metals get into the environment through discharge of waste - both domestic, 
agricultural and from auto exhausts. Following list shows the various human activities through which heavy metals get into the environment. (i) Smelting or processing of ores of metals. (ii) Mining. (iii) Burning of fossil fuels such as coal, petrol, kerosene oil.(iv)Discharging agricultural waste. (v) Discharging industrial waste.(vi)Discharging domestic waste. (vii) Discharge from auto exhausts. (viii) Using pesticides containing compounds (salts) of heavy metals (Armah, 2014). Some heavy metals are lead, cadmium, mercury, arsenic selenium, as also iron, copper, manganese, selenium, zinc, etc. All these metals have atomic number greater than 20. Low concentrations of metal like iron, copper, zinc and some others are essential for organisms. They are called 'trace metals'. On the other hand metals like lead, mercury, cadmium and some others are toxic to organisms above a certain concentration. A trace metal is defined as one which occurs in $1000 \mathrm{ppm}$ (parts per million or $\mathrm{mg} / \mathrm{lit}$ ) or less in the earth's crust. Mining activity poses significant risks for heavy metal pollution; this sector is not the only culprit in the industrial sector. Many industrial processes can generate heavy metal pollution, and in a large number of ways. Clearly, some industries will be more likely to pollute than others.

\section{Mining Activities}

Heavy metals occur in the earth's geological structures, and can therefore enter water resources through natural processes. For example, heavy rains or flowing water can leach heavy metals out of geological formations. Such processes are exacerbated when this geology is disturbed by economic activities such as mining. These processes expose the mined-out area to water and air, and can lead to consequences such as acid mine drainage (AMD). The low $\mathrm{pH}$ conditions associated with AMD mobilize heavy metals, including radio nuclides where these are present.

\section{Mineral extraction}

Mineral processing operations can also generate significant heavy metal pollution, both from direct extraction processes (which typically entail size reduction - greatly increasing the surface area for mass transfer - and generate effluents) as well as through leaching from ore and tailings stockpiles.

\section{Electronic waste}

Electronic goods Manufacturing Companies must be legally ensured to mention the disposal methods of their product in their user manual. As E-wastes are the known major source of heavy metals, hazardous chemicals and carcinogens, certainly diseases related to skin, respiratory, intestinal, immune, and endocrine and nervous systems including cancers can be prevented by proper management and disposal of E-waste. With a view to bridge the digital divide, there is exponential growth in the use of Electrical and electronic equipment (EEE) and so there is alarming effect on environment and human health when the ICT wastes are not disposed of scientifically (Mahipal et al., 2016). It produces large volumes of metal-rich effluents, will naturally be a more likely polluter than the food processing industry, for example, this is not to say that players in this industry will necessarily pollute, and it is in fact in the electroplating industry's best economic interests to minimize metal discharges, since these are inversely proportional to resource efficiency. Reducing losses by minimizing drag-out from plating baths leads to reduced metal discharges, for example. The lead-acid battery manufacturing industry is another example of an industry which can generate 
metal-rich effluents as well as airborne lead pollution which can subsequently be deposited in surface water resources (and of course on land). So clearly, where an industry uses heavy metals as key input materials, pollution risks increase (Rekha et al., 2014).

\section{Power generation plants}

A large non-point source of heavy metal pollution is coal-fired power generation, which can contaminate water resources through aerial deposition of mercury emitted from boiler flues. The industry also generates large amounts of ash which itself contains heavy metals, including uranium.

\section{Fertilizers petroleum Industry}

Cadmium is produced as an inevitable byproduct of zinc (or occasionally lead) refining, since these metals occur naturally within the raw ore. However, once collected the cadmium is relatively easy to recycle. The most significant use of cadmium is in nickel/cadmium batteries, as rechargeable or secondary power sources exhibiting high output, long life, low maintenance and high tolerance to physical and electrical stress. Cadmium coatings provide good corrosion resistance, particularly in high stress environments such as marine and aerospace applications where high safety or reliability is required; the coating is preferentially corroded if damaged. Other uses of cadmium are as pigments, stabilizers for PVC, in alloys and electronic compounds. Cadmium is also present as an impurity in several products, including phosphate fertilizers, detergents and refined petroleum products (Mustapha, 2014).

\section{Biological Practices}

The degassing of the Earth's crust, emissions from volcanoes and evaporation from natural bodies of water is the major natural source of mercury. World-wide mining of the metal leads to indirect discharges into the atmosphere. The usage of mercury is widespread in industrial processes and in various products (e.g. batteries, lamps and thermometers). It is also widely used in dentistry as an amalgam for fillings and by the pharmaceutical industry (Honglei et al., 2008).

\section{Human Exposure through Water, Food and Air}

Heavy metal pollution of surface and underground water sources results in considerable soil pollution and pollution increases when mined ores are dumped on the ground surface for manual dressing. Surface dumping exposes the metals to air and rain thereby generating much AMD. When agricultural soils are polluted, these metals are taken up by plants and consequently accumulate in their tissues (Trueby, 2003). Animals that graze on such contaminated plants and drink from polluted waters, as well as marine lives that breed in heavy metal polluted waters also accumulate such metals in their tissues, and milk, if lactating (Trueby, 1992; Peplow, 1999).

Humans are in turn exposed to heavy metals by consuming contaminated plants and animals, and this has been known to result in various biochemical disorders. In summary, all living organisms within a given ecosystem are variously contaminated along their cycles of food chain (Peplow, 1999).

\section{Heavy Metals in Water \&Effect on Human Health}

\section{Lead and Cadmium}

Patients suffer from renal failure were related to contaminant drinking water 
mainly with lead and cadmium. Lead is a dangerous element; it is harmful even in small amounts. Lead enters the human body in many ways. It can be inhaled in dust from lead paints, or waste gases from leaded gasoline. It is found in trace amounts in various foods, notably fish, which are heavily subject to industrial pollution. Some old homes may have lead water pipes, which can then contaminate drinking water. Most of the lead we take in is removed from our bodies in urine; however, there is still risk of buildup, particularly in children. Exposure to lead is cumulative over time. High concentrations of lead in the body can cause death or permanent damage to the central nervous system, the brain, and kidneys (USGAO, 2000). This damage commonly results in behavior and learning problems (such as hyperactivity), memory and concentration problems, high blood pressure, hearing problems, headaches, slowed growth, reproductive problems in men and women, digestive problems, muscle and joint pain. Studies on lead are numerous because of its hazardous effects. Lead is considered the number one health threat to children, and the effects of lead poisoning can last a lifetime. Not only does lead poisoning stunt a child's growth, damage the nervous system, and cause learning disabilities, but also it is now linked to crime and anti-social behavior in children (Rajeev Kumar et al., 2013).

\section{Nickel and Chromium}

Patients suffer from hair loss in this study were related to contaminant drinking water with nickel and chromium. Nickel is used as alloys product, nickel-plating for anticorrosion and in the manufacture of batteries. It is regarded as an essential trace metal but toxic in large amount to human health. It is considered as carcinogenic to human. Ambrose et al., (1976) reported that high-dose of nickel in rats and dogs were significantly decreasing their body weights. The pollution of water with nickel and chromium arises from industrial sources and/or agriculture activities at the studied areas. Its toxicity is enhanced in the presence of other metals such as cobalt, copper, iron and zinc in drinking water. Many studies have been published regarding nickel sensitivity in humans. Numerous other studies have been conducted to attempt to establish the relationships between nickel exposure and dermal irritation. This study reports for the first time the relationship between nickel and hair loss. Kaaber et al., (1978, 1979) reported worsening of eczema for human exposed to high level for nickel. Hair loss patients are related to contaminant drinking water and nickel can be related to derma toxicity in hypersensitive humans. On the other hand, chromium is essential to animals and human. Chromium in excess amounts can be toxic especially the hexavalent form. Chromium is used in metal alloys and pigments for paints, cement, paper, rubber, and other materials. Electroplating can release chromic acid spray and air-borne Cr-trioxide, both can result in direct damage to skin and lungs as well as chromium dust has been considered as a potential cause of lung cancer. Sub chronic and chronic exposure to chromic acid can cause dermatitis and ulceration of the skin (U.S.EPA, 1999). Long-term exposure can cause kidney and liver damage, and damage too circulatory and nerve tissue. Chromium often accumulates in aquatic life, adding also to the danger eating fish that may have been exposed to high levels of chromium.

\section{Mercury and Arsenic}

Mercury is toxic and has no known function in human biochemistry and physiology. Inorganic forms of mercury cause 
spontaneous abortion, congenital malformation and gastrointestinal disorders (like corrosive esophagitis and hematochezia). Poisoning by its organic forms, which include monomethyl and dimenthylmecury presents with erethism (an abnormal irritation or sensitivity of an organ or body part to stimulation), acrodynia (Pink disease, which is characterized by rash and desquamation of the hands and feet), gingivitis, stomatitis, neurological disorders, total damage to the brain and CNS and are also associated with congenital malformation As with lead and mercury, arsenic toxicity symptoms depend on the chemical form ingested. Arsenic acts to coagulate protein, forms complexes with coenzymes and inhibits the production of adenosine triphosphate (ATP) during respiration. It is possibly carcinogenic in com-pounds of all its oxidation states and high-level exposure can cause death. Arsenic toxicity also presents a disorder, which is similar to, and often confused with Guillain-Barre syndrome, an anti-immune disorder that occurs when the body's immune system mistakenly attacks part of the PNS, resulting in nerve inflammation that causes muscle weakness.

Arsenic is one of the most important heavy metals causing disquiet from both ecological and individual health stand points. It has a semi metallic property, is prominently toxic and carcinogenic, and is extensively available in the form of oxides or sulfides or as a salt of iron, sodium, calcium, copper, etc. Arsenic is the twentieth most abundant element on earth and its inorganic forms such as arsenite and arsenate compounds are lethal to the environment and living creatures. Humans may encounter arsenic by natural means, industrial source, or from unintended sources. Deliberate consumption of arsenic in case of suicidal attempts or accidental consumption by children may also result in cases of acute poisoning. Arsenic is a proto plastic poison since it affects primarily the sulphydryl group of cells causing malfunctioning of cell respiration, cell enzymes and mitosis.

\section{Results and Discussion}

The toxicologist have continually detected the heavy metal concentration in various water bodies, plants, vegetables, etc. Human health is directly affected by the consumption of polluted water, fish, fruits, vegetables, plants etc. which are the main sources of food for humans. Earlier studies have shown, exceeded heavy metal limit which shows that fish and drinking water is not suitable for consumption whereas somewhere it is below the permissible limit. Studies how that Industrial wastes and agricultural activities that have released hazardous and toxic constituents in the groundwater and thereby, led to contamination of drinking water in these areas. These diseases are basically related to contaminated drinking water with heavy metals such as $\mathrm{Pb}, \mathrm{Cd}, \mathrm{Cr}, \mathrm{Hg}, \mathrm{Ni}$ and As. Some of the problems related to contaminated water such as renal failure which is caused by the presence of Arsenic is a known carcinogen and can cause cancer of the skin, lungs, liver and bladder. Cadmium chronic exposure to lower levels leads to kidney diseases, lung damage, and fragile bones. Exposure to high lead levels can severely damage the brain and kidneys. Mercury cause spontaneous abortion, congenital malformation and gastrointestinal disorders. Presence of nickel in drinking water leads to hair loss. Heavy metals, if present at higher levels should be removed from drinking water for human safety. There is a need to maintain control on disposal of industrial waste in water bodies and to biomonitor the trace elements in the water and other eatables. 
In conclusion, the practice of trace element detection should be continued to avoid possible consumption of contaminated eatables. People should beware about the hazardous effects of consumption of polluted water and related eatables. It is also essential that farmers should be educated to reduce such contamination and should be encouraged to use the controlled amount of pesticides, to avoid the leaching of waste water and cultivation should be conducted in fields far away from industrial area as well as areas prone to contamination. As recommended by World Health Organization. The bioaccumulation of Heavy metals may pose great hazard to health of humans and animals that rely on the water bodies.

\section{References}

Abida Begum, Harikrishna, S., Irfanullah Khan. 2009. Int. J. Chem. Tech. Res.m CODEN(USA):IJCRGG ISSN :09744290. Vol .1, NO. 2, pp 245-249.

Armah, F.A., R. Quansah, I. Luginaah. 2014. Int. Scholarly Res. Notices, 137.

Bagul, V.R., Shinde, D.N., Chavan, R.P., Patil, C.L., Pawar, R.K. 2015. "New perspective on heavy metal pollution of water", J. Chem. Pharma. Res., 7(12): 700-705,ISSN : 0975-7384 CODEN(USA) : JCPRC5.

Danielowska, D.S. 2006. Polish J. Environ., 15(6): 943-946.

Duruibe, J.O., Ogwuegbu, M.O.C., and Egwurugwu, J.N. 2007. "Heavy metal pollution and human biotoxic effects", Int. J. Physical Sci., Vol. 2 (5), pp. 112-118, Available online at http://www.academicjournals.org/IJPS ISSN 1992 - 1950 (C) 2007 Academic Journals.

Ganagaiya, P.I., Tabudrawa, T.R., Suth, R. and Satheesrraran. 2001. 'Heavy metal contamination of Lami coast al Environment, Fiji, Southern Pacific, $J$. Natural Sci., 19: 24 - 29.

Garbarino, J.R., Hayes, H., Roth, D., Antweider, R., Brinton, T.I., Taylor, H. 1995. Contaminants in the Mississippi River, $U$. S. Geological Survey Circular 1133, Virginia, U.S.A. (www.pubs.usgs.gov/circ/ circ1133/).

Habashi, F. 1992. Environmental Issues in the Metallurgical Industry - Progress and Problems, Environmental Issues and Waste Management in Energy and Mineral Production. Balkama, Rotherdam, pp. 1143 -1153.

Honglei, L., L. Liqing, Y. Chengqing, S. Baoqing. 2008. J. Environ. Sci., 20: 390-397.

Horsfall, M.N.Jr., Spiff, A.I. 1999. Speciation of Heavy Metals in Intertidal Sediments of the Okirika River System (Nigeria), Bull. Chem. Soc. Ethiop., 13(1): 1-9.

Institute of Environmental Conservation and Research INECAR. 2000. Position Paper Against Mining in Rapu-Rapu, Published by INECAR, Ateneo de Naga University, Philippines (www.adnu.edu.ph/Institutes/Inecar/po spaper1.asp).

Jennings, G., D. Sneed, R., E. Clair, M., B St. 1996. Metals in drinking water. Published by: North Carolina Cooperative Extension service Publication no.: AG-473-1. Electronic version.

Mahipal Singh Sankhla, Mayurikumari, ManishaNandan, ShriyashMohril, Gaurav Pratap Singh, Bhaskar Chaturvedi, Rajeev Kumar. 2016. Effect of Electronic waste on Environmental \& Human health- A Review, IOSR J. Environ. Sci. Toxicol. Food Technol., (IOSR-JESTFT) eISSN: 2319-2402,p- ISSN: 2319 - 
2399. Volume 10, Issue 9 Ver. I. PP 98-104 www.iosrjournals.org.

Mustapha, O.M., O.S. Lawal. 2014. IOSR J. Appl. Chem., 7(12) II: 17-23.

Peplow, D. 1999. Environmental Impacts of Mining in Eastern Washington, Center for Water and Watershed Studies Fact Sheet, University of Washington, Seattle.

Rajeev Kumar et al. 2013. "A Review on the detection of heavy metals in water bodies, fish organs, sediment river beds", Int. J. Cur. Res. Rev., Vol 05(18).

Rajeev Kumar, R.M., Tripathi, A.K. Gupta. 2014. "Seasonal Variation of heavy metal concentration in water of River Yamuna, Allahabad, Uttar Pradesh, India", Int. J. Curr. Microbiol. App. Sci., ISSN: 2319-7706 Volume 3 Number 7, pp. 945-949 http://www.ijcmas.com.
Rekha, T.M., B. Vinod, K.V. Murthy. 2014. JCHP, 3: 111-118.

Seema Singh, Swati Lal, Jeena Harjit, Sulbha Amlathe and H.C. Kataria. 2011. Vol.3, no.5,239-246 33-40.

Trueby, P. 2003. Impact of Heavy Metals On Forest Trees From Mining Areas. In: International Conference On Mining And The Environment III, Sudbury, Ontario, Canada. (www.xcd.com/sudbury03/ prof156.html).

USGAO, 2000. Health Effect of lead in drinking water. U.S. General Accounting Office reports.

Widianarko, B., VanGestel, C.A.M., Verweij, R.A. and Van Straalen, N.M. 2000. Associations between trace metals in sediment, Water and Aguppy, Poecilia Reticulate (Peters), from urban streams of Semarang, Indonesia. Ecotoxicol. Environ. Saf., 46: 101-107.

\section{How to cite this article:}

Mahipal Singh Sankhla, Mayuri Kumari, Manisha Nandan, Rajeev Kumar, Prashant Agrawal. 2016. Heavy Metals Contamination in Water and their Hazardous Effect on Human Health-A Review. Int.J.Curr.Microbiol.App.Sci. 5(10): 759-766. doi: http://dx.doi.org/10.20546/ijcmas.2016.510.082 